\title{
A Review on Clinical Pharmacokinetics of Tamsulosin in Patients with Benign Prostatic Hyperplasia
}

\author{
Zahra Tolou Ghamari, ${ }^{1, *}$ and Hamid Mazdak ${ }^{2}$ \\ ${ }^{1}$ Isfahan Kidney Transplantation Research Center, Alzahra Research Center, Isfahan University of Medical Sciences, Isfahan, IR Iran \\ ${ }^{2}$ Department of Urology, Faculty of Medicine, Isfahan University of Medical Sciences, Isfahan, IR Iran \\ "Corresponding author: Zahra Tolou Ghamari, Isfahan Kidney Transplantation Research Center, Alzahra Research Center, Isfahan University of Medical Sciences, Isfahan, IR \\ Iran. Tel: +98-3136202088, Email: toloeghamari@pharm.mui.ac.ir
}

Received 2016 April 27; Revised 2016 May 11; Accepted 2016 May 15.

\begin{abstract}
Context: Benign prostatic hyperplasia (BPH) that disturbs aged males is described as the abundant, chronic progressive disorder usually associated with lower urinary tract symptoms. The alpha 1A-adrenergic receptor antagonist, tamsulosin (Flo$\max ($ Omnic $($ ), seems to be an appropriate management from the view point of urological surgeons. The current review aimed to evaluate the clinical pharmacological properties of tamsulosin in prostate disorders.

Evidence Acquisition: United States national library of medicine (PubMed, NLM) were searched from April 1991 to March 2016. The Mesh terms were: tamsulosin, tamsulosin pharmacokinetics in urology, tamsulosin in BPH and clinical pharmacokinetics of tamsulosin in BPH. Published clinical trials and review articles applicable to pharmacotherapy of tamsulosin in BPH were reviewed. Results: In patients with mild international prostate symptom score $(<8)$ to moderate symptoms of BPH, initial treatment with an alpha 1-adrenergic antagonist monotherapy were useful. With a half-life of $9-13$ hours, the oral bioavailability of drug was reported $100 \%$. The drug is metabolized by liver. Excretion through renal was reported $76 \%$. Initial dose of drug was $0.4 \mathrm{mg} / \mathrm{day}$ and the maximum dose was reported $0.8 \mathrm{mg}$ /day. The drug could cause dizziness, sever drowsiness and problems in thinking, driving and many other complications. Other serious adverse reactions could be mentioned as hives, rash, itching, and difficulty in breathing, swelling of face, lips, tongue and throat. Tamsulosin therapy should be stopped in patients who experience hypotension.

Conclusions: To treat BPH therapeutically, it is necessary to stabilize severities of the patient's symptoms with potential side effects of the treatment. Tamsulosin blocks alpha 1-receptors in smooth muscles both in the bladder neck and prostate, which leads to relaxation and subsequently less resistance to urinary flow. By advancement of tamsulosin, pharmacotherapy strategies could provide more appropriate guideline treatments; therefore, in Isfahan, Iran, innovative medical treatment for BPH was suggested based on both pharmacological and surgical clinical trials.
\end{abstract}

Keywords: Tamsulosin, Pharmacokinetics, Pharmacotherapy, Prostate, Benign

\section{Context}

Benign prostatic hyperplasia (BPH) is the most common proliferative disorder among aging males. Androgens play a major role in the development and growth of the male genital tract preferring differentiation and propagation of stromal and epithelial cells of the prostate gland. According to the published articles, variation between growth factors and the steroid hormone may change the equilibrium between proliferation and cell death prominent to progress of BPH (1). Tamsulosin was first introduced in 1996 and the United States expired its patent in 2009. Other brand names of the drug are Flomax® and Omnic®. It was first explored by Yamanouchi Pharmaceuticals that is currently a division of Astella Pharma and was accepted by U.S food and drug administration (FDA) in 2010 (2). Long-term benefit of tamsulosin pharmacotherapy (either monotherapy or polypharmacy) needs a well-meaning of clinical pharmacokinetics parameters in terms of absorption, distribution and elimination phase after tamsulosin-exposure. Table 1 shows pharmacokinetics data related to tamsulosin. With a molar mass of 408.51, the formula of drug is $\mathrm{C} 2 \mathrm{OH} 28 \mathrm{~N} 2 \mathrm{O} 5 \mathrm{~S}$. Its route of administration is oral with $100 \%$ bioavailability. Half-life of drug seems to vary from 9 - 13 hours depending on different individuals. The drug is metabolized through liver and $76 \%$ of the metabolized form of the drug is excreted through kidneys $(2,3)$. Study showed that there was no major alteration in the pharmacokinetics of tamsulosin $\mathrm{HCl}$ between pediatric patients (age range 2 - 16 years) and adults when the effect of body weight was considered (4). Related to the mechanism of action of tamsulosin, there are alpha $1 \mathrm{~A}$-adrenergic and alpha $1 \mathrm{~B}$-adrenergic receptors, in the prostate and blood vessels, respectively. Therefore, tamsulosin could be used as an antagonist of alpha $1 \mathrm{~A}$-adrenergic receptor for symptomatic management of $\mathrm{BPH}$. By blocking alpha $1 \mathrm{~A}$-adrenergic receptors in the neck of bladder and prostate, the repose in smooth mus- 
cles could cause less confrontation to urinary flow (5). Djavan et al. (6) noted that combination therapy by dutasteride and tamsulosin was a highly efficacious treatment for $\geq 4$ years, in patients with moderate-to-severe lower urinary tract symptoms (LUTs) due to BPH. The study on the efficacy of $0.2 \mathrm{mg} /$ day tamsulosin in patients with nocturia associated with LUTs/BPH by Yoshida et al. (7), showed significant clinical improvements in the nocturnal frequency within the frequency volume chart and the international prostate symptom score. There was a significant difference in the hours of uninterrupted sleep, the intermission among the time of sleeping and the first occurrence of nighttime voiding, the capacity of urine in the first nightly voiding incident, nocturnal urine capacity, nocturnal polyuria index, daily urine volume, maximum and middling flow rates and post-void remaining. Finally as suggested by previously published articles, the new strategy based on pharmacotherapy that used alpha 1-adrenergic antagonists such as tamsulosin seems to be more efficacious for short and long-term treatment of BPH than conventional drug-therapy strategies.

Table 1. Clinical Pharmacological Properties of Tamsulosin

\begin{tabular}{|lc}
\hline Variables & Values \\
\hline Route of administration & Oral \\
\hline $\begin{array}{l}\text { Dosage: Once daily prescription of } 0.4 \text { or } 0.8 \text { mg shows } \\
\text { maintenance of efficacy for up to } 6 \text { years. }\end{array}$ & \\
\hline Bioavailability $(\mathbf{F})$ & $100 \%$ \\
\hline Elimination half-life $\left(\mathbf{t}_{\mathbf{1} / \mathbf{2}}\right)$ & $9-13 \mathrm{~h}$ \\
\hline Metabolism & hepatic \\
\hline Excretion & $76 \%$ renal \\
\hline $\begin{array}{l}\text { Reported side effects: Dizziness, abnormal ejaculation } \\
\text { (most common) and asthenia, postural hypotension and } \\
\text { palpitations }(\text { less frequently) }\end{array}$ & \\
\hline
\end{tabular}

As the international burden of prostate disorders is increasing, in addition to lifestyle modifications (8-10), understanding safety, efficacy and side-effects of tamsulosin may help timely intervention of disease and proper treatment in males with prostate disorders. Therefore, clarifying effectiveness of tamsulosin in the patients with BPH was the main objective of the current review.

\section{Evidence Acquisition}

According to the authors' previous clinical experiences associated with efficacy, safety and side-effects of drugs used in clinical practice (11-15), United States national library of medicine (PubMed, NLM) were searched. The
Mesh terms were: 1) tamsulosin, 2) tamsulosin pharmacokinetics in urology, 3) tamsulosin in BPHand 4) clinical pharmacokinetics of tamsulosin in $\mathrm{BPH}^{\prime}$. There were: 1) 1506 articles from September 1988 to November 2015, 2) 17 articles from December 1995 to October 2014,3) 760 articles from April 1991 to March 2016 and 4) 18 articles from December 1996 to May 2015. Research and review articles relevant to clinical and pharmacological properties of tamsulosin were reviewed up to March 2016.

\section{Results}

Considering the disorders of prostate, BPH is the fourth most frequently identified health disorder in the elderly (6) and about 8 million patients are assessed to visit an urologist with the judgment of primary or secondary BPH (16). Because of infection, the shadowed and untreated acute inflammation could lead to chronic inflammation that subsequently results in changes in hormonal and metabolic states of males' body $(1,17)$. Bashir in 2015 reported that the most common malignancy among males worldwide is the prostate cancer. An estimated 1.1 million new cases and 307,000 deaths were reported in 2012. Advancing age, race, positive family history, diet based use of fat items, obesity, physical activity, sexual activity, smoking and occupation are mentioned as the highest risk factors for prostate cancer (10). The selective adrenoceptor (alpha1A) blocker, tamsulosin by the relaxation of smooth muscles, predominate in the prostate gland, prostatic capsule, prosthetic urethra and bladder that could be subsequently associated with an improvement of maximal urine flow (Qmax) and alleviation of urinary tract systems in patients with BPH. Prescription of 0.4 or $0.8 \mathrm{mg} /$ day shows maintenance of efficacy for up to six years. Dizziness and abnormal ejaculation are noted as the most common adverse events, with asthenia, postural hypotension and palpitations reported less frequently (18-21). Zhong et al. (19), studied costs and effectiveness of treatments for BPH, including polypharmacy based on finasteride and tamsulosin, transurethral 2 micron laser resection of the prostate and transurethral resection of the prostate (TURP). It was reported that polypharmacy was the better option for patients with $\mathrm{BPH}$, and the transurethral 2 micron laser resection of the prostate, the cost of which is lower than that of pharmaceuticals, was a safe and effective surgery. Yu et al. (20), investigated that a combination of tamsulosin plus low dose sildenafil could be a beneficial treatment for post implantation progression of LUTS. The study of efficacy and safety of tamsulosin $0.2 \mathrm{mg}$ by a meta-analysis and meta-regression performed by Shim et al. (21), clarified that tamsulosin $0.2 \mathrm{mg}$ has similar efficacy and fewer adverse events compared with other alpha-blockers as an ini- 
tial treatment strategy for males with lower urinary tract symptoms. Dimitropoulos et al. (22) confirmed that polytherapy based on a fixed-dose of tamsulosin $0.4 \mathrm{mg}$ and dutasteride $0.5 \mathrm{mg}$ is approved and released for clinical use in males with BPH. Pharmacotherapy based on polytherapy used solifenacin and tamsulosin also communicated with progress in patient detailed outcomes such as urinary nerve growth factor and creatinine levels (23). Investigation of Choi et al. (24) showed that combination therapy comprising of $\alpha$-blockers and $5 \alpha$-reductase inhibitors in patients with a transitional zone index (TZI) of $\geq 0.5$ is expected improvement linked to greater maximum urinary flow rates (Qmax). As a final point according to the published articles tamsulosin-therapy based on inter- and intra- individual assumption for BPH, seem to be safe and effective to improve the related symptoms and quality of life in patients.

\section{Conclusions}

The challenges related to pharmacotherapy and surgical strategy of BPH is altering due to a superior thought about the disorder and the growth of the practical perception of LUTS (25). The subtype-selective alpha 1A- and alpha $1 \mathrm{D}$-adrenoceptor antagonist tamsulosin-therapy were useful clinical management in the population with BPH. The study on patients receiving tamsulosin 0.4 or $0.8 \mathrm{mg} /$ day specified the preserve of effectiveness for up to six years. Tamsulosin $0.4 \mathrm{mg} /$ day was of comparable efficiency to alfuzosin $2.5 \mathrm{mg}$ three times daily, with fewer inclinations to cause hypotensive effects, in a double-blind randomized 12-week trial (18). The urodynamic results of tamsulosin as an alpha1A antagonism, in patients with lower urinary tract symptoms (LUTS) conventionally linked to BPH as a matter of urological subject are discussed in terms of efficacy and side-effects. The studies in 2016 showed that primary end-point of variation in bladder outlet obstruction index (BOOI) by a mean change of $-14.27(\mathrm{P}<0.002)$ related to pharmacotherapy used tamsulosin (26). The results of randomized clinical trials on 118 patients with symptomatic BPH within two groups related to prescription of $0.2 \mathrm{mg}$ tamsulosin alone and group two with $0.5 \mathrm{mg}$ dutasteride daily for 12 months showed that in group two, there was a considerably superior reduction in prostate volume $(\mathrm{P}<0.001)$, TZI volume $(\mathrm{P}<0.001)$ and prostatespecific antigen (PSA; P < 0.001) (24). Hayashi et al. (27), confirmed that ejaculation dysfunction may be attributed to the $\alpha 1 \mathrm{~A}-\mathrm{AR}$ antagonist-mediated suppression of nerveevoked contractions in the seminal vesicle, as the early tightening started by neuronal excitations were covered by silodosin and tamsulosin. The study on the effectiveness of single half-dose silodosin and single full-dose tam- sulosin in Japanese males with LUTS/BPH showed that prescription of single half-dose silodosin had a similar efficacy to full-dose tamsulosin (28). To determine the preliminary necessity for pharmacotherapy strategy or surgical intervention, it is recommended to verify $\mathrm{BPH}$ patients with high risk of alpha 1-adrenoceptor antagonist monotherapy failure based on sonographic measurements of bladder wall thickness, ultrasound estimated bladder weight and intravesical prostatic protrusion (29). In conclusion, tamsulosin-therapy seems to be a respected beneficial decision (1-31) with both verified and impending compensations over older nonselective agents, in the supervision of patients with LUTS connected with BPH.

\section{Acknowledgments}

Authors would like to express special thanks to the Isfahan University of Medical Sciences.

\section{Footnotes}

Authors' Contribution: Zahra Tolou Ghamari and Hamid Mazadk: study concept, literature review, acquisition of data, design, analysis and interpretation of manuscript, drafting of the manuscript and critical revision of the manuscript for intellectual content.

Funding/Support: Isfahan University of Medical Sciences supported this study.

\section{References}

1. La Vignera S, Condorelli RA, Russo GI, Morgia G, Calogero AE. Endocrine control of benign prostatic hyperplasia. Andrology. 2016;4(3):404-11. doi: 10.1111/andr.12186. [PubMed: 27089546].

2. Food and Drug Administration (FDA). FDA approves first generic tamsulosin to treat enlarged prostate gland (Press release). U.S.: Food and Drug Administration (FDA); 2010.

3. Michel MC, Korstanje C, Krauwinkel W, Kuipers M. The pharmacokinetic profile of tamsulosin oral controlled absorption system (OCAS®). Eur Urol Supplement. 2005;4(2):15-24.

4. Tsuda Y, Tatami S, Yamamura N, Tadayasu Y, Sarashina A, Liesenfeld $\mathrm{KH}$, et al. Population pharmacokinetics of tamsulosin hydrochloride in paediatric patients with neuropathic and non-neuropathic bladder. Br J Clin Pharmacol. 2010;70(1):88-101. doi: 10.1111/j.13652125.2010.03662.x. [PubMed: 20642551].

5. Price D. Potential mechanisms of action of superselective alpha(1)adrenoceptor antagonists. Eur Urol. 2001;40 Suppl 4:5-11. [PubMed: 11786674].

6. Djavan B, Handl MJ, Dianat S. Combined medical treatment using dutasteride and tamsulosin for lower urinary tract symptoms suggestive of benign prostatic hyperplasia. Expert Opin Pharmacother. 2010;11(15):2535-47. doi: 10.1517/14656566.2010.516901. [PubMed: 20854184]. 
7. Yoshida M, Inadome A, Masunaga K, Nagata T, Yoshiyasu T. Effectiveness of tamsulosin hydrochloride and its mechanism in improving nocturia associated with lower urinary tract symptoms/benign prostatic hyperplasia. Neurourol Urodyn. 2010;29(7):1276-81. doi: 10.1002/nau.20872. [PubMed: 20878997].

8. Cuzick J, Thorat MA, Andriole G, Brawley OW, Brown PH, Culig Z, et al. Prevention and early detection of prostate cancer. Lancet Oncol. 2014;15(11):484-92. doi: 10.1016/S1470-2045(14)70211-6. [PubMed: 25281467].

9. Haas GP, Delongchamps N, Brawley OW, Wang CY, de la Roza G. The worldwide epidemiology of prostate cancer: perspectives from autopsy studies. Can J Urol. 2008;15(1):3866-71. [PubMed: 18304396].

10. Bashir MN. Epidemiology of Prostate Cancer. Asian Pac J Cancer Prev. 2015;16(13):5137-41. [PubMed: 26225642].

11. Tolou-Ghamari Z. Antiepileptic drugs (AEDs) polypharmacy could lead to buried pharmacokinetic interactions due to CYP450. Drug Metab Lett. 2012;6(3):207-12. [PubMed: 23140557].

12. Tolou-Ghamari Z, Mehvari-Habibabadi J, Palizban A. Evidence-Based Pharmacotherapy of Epilepsy.. Archives of Neuroscience. 2015;2(1).

13. Tolou-Ghamari Z. Efficacy and Toxicity of Rituximab in Multiple Sclerosis. Arch Neurosci. 2016;3(1).

14. Tolou-Ghamari Z, Mortazavi M, Palizban AA, Najafi MR. The investigation of correlation between Iminoral concentration and neurotoxic levels after kidney transplantation. Adv Biomed Res. 2015;4:59. doi: 10.4103/2277-9175.151876. [PubMed: 25802828].

15. Tolou-Ghamari Z. Preliminary Evidence-Based Pharmacotherapy of Mitoxantrone for Multiple Sclerosis in an Iranian Population. Thrita. 2015;4(3).

16. Izumi K, Mizokami A, Lin WJ, Lai KP, Chang C. Androgen receptor roles in the development of benign prostate hyperplasia. Am J Pathol. 2013;182(6):1942-9. doi:10.1016/j.ajpath.2013.02.028. [PubMed: 23570837].

17. Gurel B, Lucia MS, Thompson IM, Goodman PJ, Tangen CM, Kristal $\mathrm{AR}$, et al. Chronic inflammation in benign prostate tissue is associated with high-grade prostate cancer in the placebo arm of the prostate cancer prevention trial. Cancer Epidemiol Biomarkers Prev. 2014;23(5):847-56. doi: 10.1158/1055-9965.EPI-13-1126. [PubMed: 24748218].

18. Dunn CJ, Matheson A, Faulds DM. Tamsulosin: a review of its pharmacology and therapeutic efficacy in the management of lower urinary tract symptoms. Drugs Aging. 2002;19(2):135-61. [PubMed: 11950378].

19. Zhong C, Wen W, Xia S. [Cost and effectiveness analysis of treatments for benign prostatic hyperplasia]. Zhonghua Yi Xue Za Zhi. 2016;96(4):289-92. doi: 10.3760/cma.j.issn.0376-2491.2016.04.013. [PubMed: 26879791].

20. Yu YD, Kang MH, Choi CI, Shin HS, Oh JJ, Park DS. Clinical efficacy of combination therapy with an alpha blocker and low-dose sildenafil on post-therapy lower urinary tract symptoms after low-dose- rate brachytherapy for prostate cancer. World J Urol. 2016;34(9):126974. doi: 10.1007/s00345-016-1777-7. [PubMed: 26868648].

21. Shim SR, Kim JH, Chang IH, Shin IS, Hwang SD, Kim KH, et al. Is Tamsulosin $0.2 \mathrm{mg}$ Effective and Safe as a First-Line Treatment Compared with Other Alpha Blockers?: A Meta-Analysis and a Moderator Focused Study. Yonsei Med J. 2016;57(2):407-18. doi: 10.3349/ymj.2016.57.2.407. [PubMed: 26847294].

22. Dimitropoulos K, Gravas S. Fixed-dose combination therapy with dutasteride and tamsulosin in the management of benign prostatic hyperplasia. Ther Adv Urol. 2016;8(1):19-28. doi: 10.1177/1756287215607419. [PubMed: 26834837].

23. Chan R, Munoz A, Wenker EP, Whipple M, Miles B, Boone TB. Solifenacin and Tamsulosin Combination Therapy Decreases Urine Nerve Growth Factor/Creatinine Levels in Men. Urology. 2016;91:150-3.

24. Choi JD, Kim JH, Ahn SH. Transitional Zone Index as a Predictor of the Efficacy of alpha-Blocker and 5alpha-Reductase Inhibitor Combination Therapy in Korean Patients with Benign Prostatic Hyperplasia. Urol Int. 2016;96(4):406-12. doi: 10.1159/000442995. [PubMed: 26824527].

25. Carrero-Lopez VM, Cozar-Olmo JM, Minana-Lopez B. Benign prostatic hyperplasia and lower urinary tract symptoms. A review of current evidence. Actas Urol Esp. 2016;40(5):288-94

26. Fusco F, Palmieri A, Ficarra V, Giannarini G, Novara G, Longo N et al. alpha1-Blockers Improve Benign Prostatic Obstruction in Men with Lower Urinary Tract Symptoms: A Systematic Review and Metaanalysis of Urodynamic Studies. Eur Urol. 2016;69(6):1091-101. doi: 10.1016/j.eururo.2015.12.034. [PubMed: 26831507].

27. Hayashi T, Takeya M, Nakamura K, Matsuoka K. Effects of Silodosin and Tamsulosin on the Seminal Vesicle Contractile Response. Low Urin Tract Symptoms. 2016;8(1):55-61. doi: 10.1111/luts.12072. [PubMed 26789544]

28. Takeshita H, Moriyama S, Arai Y, Washino S, Saito K, Chiba K, et al Randomized Crossover Comparison of the Short-Term Efficacy and Safety of Single Half-Dose Silodosin and Tamsulosin Hydrochoride in Men With Lower Urinary Tract Symptoms Secondary to Benign Prostatic Hyperplasia. Low Urin Tract Symptoms. 2016;8(1):38-43. doi: 10.1111/luts.12106. [PubMed: 26789541].

29. Ahmed AF. Sonographic Parameters Predicting the Outcome of Patients With Lower Urinary Tract Symptoms/Benign Prostatic Hyperplasia Treated With Alpha1-Adrenoreceptor Antagonist. Urology. 2016;88:143-8. doi: 10.1016/j.urology.2015.11.017. [PubMed: 26607685].

30. Radman M, Mirhoseini H, Rezahosseini O, Panahi A, Bidaki R, JamaliPaghale M. Comparison of Urinary Symptoms in Patients with Benign Prostatic Hyperplasia after Prostatectomy for Prostates weighted more and less than 50 Grams. ZJRMS. 2014;16(1):102.

31. Tolou Ghamari Z, Mehavari Habibabadi J, Palizban AA. Evidence-Based Pharmacotherapy of Epileps. Arch Neurosci. 2015;2(1):e18468. doi: 10.5812/archneurosci.18468. 